\title{
Factor structure and proposed scoring revision of the Three- Dimensional Psychological Pain Scale
}

\author{
Ronald R. Holden ${ }^{1}$, Rui C. Campos ${ }^{2}$, Christine E. Lambert ${ }^{1}$, Ana Simões ${ }^{2}$, Sara Costa ${ }^{2}$, Ana \\ Sofia Pio², Joana Spínola², \& Diandra Marques ${ }^{2}$ \\ ${ }^{1}$ Queen's University, Kingston, Ontario, Canada \\ 2 University of Évora, Évora, Portugal
}

\begin{abstract}
The development of psychometrically sound measures to assess mental pain are important because research has consistently demonstrated a robust relationship to suicide risk. The current research evaluated the Three-Dimensional Psychological Pain Scale (TDPPS) structure, a suicide-relevant measure intended to articulate pain into affective, cognitive, and behavioral facets. As the first Western study to evaluate the TDPPS structure with non-Chinese respondents, six samples comprising 1,627 adults participated. Neither confirmatory factor analyses nor exploratory structural equation modeling supported the hypothesized three-dimensional structure of the TDPPS but, instead, identified two dimensions: pain escape and pain emotions. Scales based on these two dimensions demonstrated replicability in crossvalidation and score internal consistency reliability. Furthermore, validity for scores on these two scales was confirmed through moderate associations with another pain measure and scales of suicidal behavior and depression. Findings extend knowledge of TDPPS's structure of psychological pain and suggest a scale scoring revision.
\end{abstract}

Keywords: Three-Dimensional Psychological Pain Scale; Pain escape; Pain emotions; Suicidal behaviors.

Estrutura factorial e proposta de revisão do sistema de cotação da Escala Tridimensional de Dor Psicológica: 0 desenvolvimento de instrumentos de medida adequados do ponto de vista psicométrico para a avaliar a dor psicológica é importante, dado que a investigação tem demonstrado a existência de uma relação robusta com o risco suicidário. 0 presente estudo avaliou a estrutura da Escala Tridimensional de Dor Psicológica (TDPPS), uma medida relevante para o suicídio, destinada a avaliar três facetas da dor psicológica: afetivas, cognitivas e comportamental. Participaram seis amostras num total de 1,627 adultos. Nem uma análise fatorial confirmatória nem a modelagem de equações estruturais exploratória sustentaram a hipótese da estrutura tridimensional do TDPPS; antes identificaram duas dimensões: fuga da dor e emoção de dor que demonstraram replicabilidade numa validação cruzada e adequada consistência interna. Além disso, a validade dos resultados nessas duas escalas foi confirmada por associações com outra medida de dor e escalas de comportamento suicida e depressão. Os resultados ampliam o conhecimento da estrutura do TDPPS.

Palavras-chave: Escala Tridimensional de Dor Psicológica; Fuga da dor; Emoção de dor; Comportamentos suicidários.

Worldwide, suicide takes the lives of more than 800.000 persons annually (World Health Organization, 2021). In Portugal, 1061 persons died by suicide in 2017, representing 1\% of the country's mortality (National Institute of Statistics, 2019). Understanding the factors related to suicide risk and assessing those using sound psychometric measures is an important clinical task goal. Recent reviews (Ducasse et al., 2018; Verrocchio et al., 2016) have emphasized the role of psychological pain in understanding suicidality. Further, in his model of suicide, Shneidman (1993) proposed that suicide is caused by unbearable psychological pain that he termed psychache. Psychache is a state of deep anguish resulting from frustration of basic psychological needs; it is a more primal, savage mental pain than occurs in general distress or depression, and escaping from this pain is an important motivation for attempting suicide (Holden et al., 1998). Although conceptually overlapping with depression and hopelessness, psychache is a factor analytically distinct from these other constructs (Troister \& Holden, 2013).

\footnotetext{
${ }^{1}$ Correspondence address: Rui C. Campos, Departamento de Psicologia, Universidade de Évora, Apartado 94, $7002-554$ Évora, Portugal. Email: rcampos@uevora.pt
} 
Ducasse et al. (2018) indicate that higher levels of psychological pain are linked both to suicidal ideation and to suicidal actions. The added value of assessing psychological pain relative to risk indicators such as depression to predict suicidal behaviors has been demonstrated (Berlim et al., 2003; Demirkol et al., 2019). Further, mental pain assessment has outperformed the assessment of depression and hopelessness for screening suicide risk (Troister et al., 2015). Mental pain has also been found to fully and partially mediate the links between general distress and suicide ideation in a community sample (Campos et al., 2016). Furthermore, mental pain has also been shown to statistically predict suicide attempts (Leenaars \& Lester, 2005) and ideation (Flynn \& Holden, 2007) among students.

In asserting that psychological pain is a core clinical feature for suicide, Verrocchio et al. (2016) advocate for routinely evaluating mental pain when suicide risk is clinically assessed. Evaluation of psychological pain as a suicide indicator also has merit when assessing clients who mask (Shneidman, 1994) or who need to appear flawless to others (Roxborough et al., 2012). With this accumulating evidence, tools for assessing mental pain continue to develop and require verification of their structure and scale properties. As such, the current investigation evaluated a promising Chinese measure of psychological pain for its structural integrity in Western populations.

Instruments for assessing psychological pain are available, including the Psychache Scale (Holden et al., 2001) and the Mee-Bunney Psychological Pain Assessment Scale (Mee et al., 2011). More recently, Li et al. (2017) developed the Three-Dimensional Psychological Pain Scale (TDPPS) that, unlike other psychological pain scales that are unidimensional, attempts to differentiate psychological pain into affective, cognitive, and behavioral facets, based on the Li et al. (2014) three-dimensional psychological pain model of suicide. According to this model, the affective dimension involves subjective and bodily symptoms that represent painful feelings. The cognitive dimension relates to memories of past traumas such as loss, frustration, and social exclusion. The avoidance component is the tendency to view suicide as the means to escape from psychological pain, and it is hypothesized to be the most important predictor of suicidal motivation. Overall, the Li et al. $(2014,2017)$ model attempts to partition more finely the construct of psychological pain than has been done previously by more unidimensional measures that focus primarily on affect. To date, only a few studies have examined this three-dimensional pain model using the 17-item TDPPS. Research has shown that pain avoidance (i.e., the behavioral scale of the TDPPS) may be a primary motivator for suicidal behaviors, even in the absence of depression (Li et al., 2014; Xie et al., 2014). The pain avoidance subscale has displayed superior performance in accurately identifying suicide attempters among patients with major depressive disorder compared to measures of impulsivity, depression, hopelessness, psychache, and the acquired capability for suicide (Sun et al., 2020).

Importantly, using the same measure (i.e., the TDPPS), this finding has been replicated but just in a few studies in Western societies (Campos, Holden, et al., 2019; Campos, Simões, et al., 2019). Although the TDPPS, in general, and its Pain Avoidance scale, in particular, have demonstrated merit, the TDPPS factor structure has not been well established, particularly outside of its Chinese origins. To our knowledge, the only structural analysis of the TDPPS items has been that of Li et al. (2017), who, for a sample of 1,185 Chinese undergraduate students responding to the Chinese version of the TDPPS, reported that an exploratory factor analysis yielded three components explaining 55.5\% of the total variance and that a confirmatory factor analysis demonstrated adequate fit for the hypothesized three-factor model. ${ }^{2}$

As such, the purpose of the present study was to investigate the structure of the TDPPS in Western samples and with non-Chinese versions of the measure. Testing and replicating the structure of the measure could support its use with Western populations. It would also allow for evaluating the Li et al. (2014) three-dimensional model and, thus, contribute to clarifying the dimensionality of psychological pain as a construct to be assessed in practice and research. We hypothesized that a 3-factor solution would replicate across samples, that scores for the three reliable dimensions would relate with another psychological pain measure, the Psychache Scale, and a related but distinct construct, depression. We also hypothesized that all three dimensions, especially pain avoidance, would explain significant, unique variance in suicidal behaviors.

\section{METHOD}

\section{Participants}

The examination of the TDPPS used six distinct data sets. Sample 1 consisted of 331 undergraduate volunteers (186 women, 145 men) at a midsize Portuguese university ( $>95 \%$ Caucasian) who volunteered and were not compensated. Mean age was 19.89 years $(S D=1.74$, Median $=20)$. Sample 2 included 232 Portuguese community participants (148 women, 84 men) recruited to participate in a study of

\footnotetext{
${ }^{2}$ Li et al. (2017) do not report their confirmatory factor analysis solution and, as such, invariance with the obtained solution in the current
} study could not be evaluated. 
psychological variables, suicidal ideation, and risk behaviors. They were not compensated. Participants had a mean age of 34.98 years $(S D=11.80$, Median $=32)$. Sample 3 consisted of 384 undergraduate volunteers (193 women, $191 \mathrm{men}$ ) at a midsize Portuguese university ( $>95 \%$ Caucasian) who were not compensated. These participants had a mean age of 19.62 years $(S D=2.20$, Median $=19)$. Sample 4 included 228 students (204 women, 23 men, 1 unreported) at a midsize Canadian university ( $80 \%$ Caucasian) who received psychology course credit for participation. Mean age was 18.36 years $(S D=1.12$, Median $=18)$. Sample 5 comprised 247 undergraduates ( 219 women, $28 \mathrm{men}$ ) at a midsize Canadian university ( $>80 \%$ Caucasian) with a mean age of 20.06 years $(S D=5.69$; Median $=18)$ who, for participation, received introductory psychology course credit. Sample 6 included 207 American community participants (136 men, 70 women, 1 unreported) recruited through Amazon's Mechanical Turk and were paid 5.00 USD to participate in a study on personality, motivations, life history, and suicide ideation. The mean age of these participants was 33.37 years $(S D=8.76$, Median $=31)$.

\section{Measures}

Three-Dimensional Psychological Pain Scale (TDPPS). The TDPPS (Li et al., 2014) is a 17-item inventory assessing psychological pain within three facets: cognitive (e.g., "I feel rejected and misunderstood by people around me, which is the cause of my pain"), affective (e.g., "The pain I feel is in my mind and is much more severe than any physical pain"), and avoidance (e.g., "My pain hurts so badly that death could be the only way to escape from it"). Items are answered on 5-point Likert ratings ranging from 1 - "not at all" to 5 - "extremely so." Although the development of the TDPPS has not been fully published, Li et al. (2017) have reported TDPPS scale score coefficient alpha reliabilities over .76. They have shown that scale scores can differentiate among suicide ideators, major depressive disorder patients, and healthy controls. As elsewhere detailed (Campos, Holden, et al., \& 2019; Campos, Simões, et al., 2019), the TDDPS was translated to Portuguese from an English version sent by authors of the original Chinese version. Several clinical psychologists and a bilingual translator, who performed a back-translation, participated in the translation process.

Psychache Scale. The Psychache Scale (Holden et al., 2001) is a 13-item measure of psychological pain (e.g., "My soul aches") answered on 5-point ratings varying from 1 (never or strongly disagree) to 5 (always or strongly agree). Scale scores have strong reliability in samples of university $(\alpha=.94$; Troister \& Holden, $2010)$ and offender $(\alpha=.95$; Mills et al., 2005) participants. Validity for scale scores has been shown through correlations with indices of suicide ideation $(r=.65)$, suicide attempts $(r=.45)$, likelihood of future suicide commission $(r=.33)$, and self-injury $(r=.50)$ (Holden et al., 2001). Samples 1, 2, and 3 responded to the scale's Portuguese version (Campos et al., 2018). Results with the Portuguese version supported the unidimensional scoring of the scale, its ability to differentiate between individuals at-risk for suicide from individuals not at-risk, its relationship with different but related constructs, and its ability to predict suicide ideation statistically. Alpha reliability coefficients in the current samples were .90, .94, .93, .96, .96, and .98, respectively for the six samples.

Suicidal Behaviors Questionnaire-Revised (SBQ-R). The SBQ-R (Osman et al., 2001) includes four multiple-choice items (e.g., "Have you ever thought about or attempted to kill yourself") assessing: a history of suicide ideation and/or attempts; recent suicide ideation (i.e., during the past year); the communication of suicidal intentions to others; and the likelihood of a future suicide attempt. Item 1 has six response options, item 2 has five response options, item 3 has five response options, and item 4 has seven response options. SBQ-R scale scores have acceptable internal consistency reliability across multiple samples (alpha reliability coefficients from .76 to .87). They have been effective in differentiating suicidal from non-suicidal individuals (Osman et al., 2001). Samples 1, 2, and 3 responded to the questionnaire's Portuguese version (Campos \& Holden, 2019). Results have supported the scale internal consistency, its unidimensionality, and both concurrent and 5-month predictive validity. Alpha reliability coefficients in the current six samples were $.75, .72, .82, .80, .82$, and .82 , respectively.

Center for Epidemiologic Studies Depression Scale (CES-D). The CES-D (Radloff, 1977) is a 20-item scale measuring the previous week's frequency of depressive symptoms. Items (e.g., "I felt that everything I did was an effort") are responded to on 4-point Likert ratings from 0 ("Never or very rarely - less than 1 day") to 3 ("Very frequently or always - 5-7 days"). Radloff (1977) has reported scale score coefficient alpha reliabilities of .85 and .90 for community and clinical samples, respectively. For scale score validity, Erford et al. (2016) found a .72 correlation between Beck Depression Inventory-II and CES-D scale scores across 11 studies. Samples 1, 2, and 3 responded to the scale's Portuguese version (Gonçalves \& Fagulha, 2004). Coefficient alpha for the Portuguese version values have ranged from 0.85 to 0.92 in several Portuguese 
samples. Alpha reliability coefficients in the current study were .92, .91, .91, .92, .93, and .95, respectively, for the six samples.

\section{Procedure}

For confirmatory and exploratory analyses, this examination of the TDPPS re-analyzed six distinct data sets from Campos, Holden, et al. (2019), Campos, Holden, Spínola, et al. (2019), and Holden et al. (2020). Participants supplying data were all treated in accord with the ethical principles of the American Psychological Association. Data collection procedures were approved by the two institutional ethics research boards associated with the researchers' universities and took approximately 2 to 3 weeks per sample.

All individuals provided informed consent. Samples 1 and 3 completed printed versions of questionnaires while samples 2, 4, 5, and 6 completed materials online. All participants received debriefing material regarding available counseling resources and including telephone numbers for participants wishing to contact a mental health professional.

\section{Data Analytic Plan}

Data analysis focused on eight steps:

1. A maximum likelihood confirmatory factor analysis (CFA) was computed for each sample. The model tested was the three-factor model proposed by Li et al. (2017). Sellbom and Tellegen (2019) indicate RMSEA and SRMR values of .06-.08 as acceptable fit with values $<.06$ as good fit, and CFI and TLI values of $.90-.94$ as acceptable fit with values of $\geq .95$ being good fit.

2. Because CFA can be regarded as overly stringent in not permitting items to cross-load (Marsh et al., 2014), the three-factor model in the first step was also tested using maximum likelihood exploratory structural equation modeling (ESEM). The ESEM model specified three factors but, unlike CFA, permitted non-zero cross-loadings.

3. If the model from the CFA or ESEM analyses didn't fit adequately, principal components analysis was undertaken guided by parallel analysis (Zwick \& Velicer, 1986) and the eigenvalue-greater-than-one heuristic for determining the number of dimensions. An orthogonal rotation of the solution was used to reduce intercorrelations among subsequently developed scales. ${ }^{3}$ This was done for two samples combined (Samples 1 and 4) to leave four independent samples for assessing cross-validation.

4. Item selection in developing scales maximized an item efficiency index (IEI; Holden, 1996; Jackson et al., 1989; Waring et al., 1998), again to reduce intercorrelations among developed scales:

$$
\text { IEI }_{\mathrm{i}}=A_{\mathrm{ih}}^{2}-\sum_{\mathrm{c}=1}^{\mathrm{nc}} \mathrm{A}_{\mathrm{ic}}^{2}, \quad \mathrm{c} \neq \mathbf{h}
$$

$\mathrm{IEI}_{\mathrm{i}}=$ Item Efficiency Index for the $i$ th item

$\mathrm{A}_{\mathrm{ih}}=$ is the $i$ th item's loading on its most salient component

$\mathrm{A}_{\mathrm{ic}}=$ is the $i$ th item's loading on the other component(s)

nc $=$ the number of components

5. CFAs for each sample were undertaken based on items scored on the developed scales.

6. ESEMs for each sample were undertaken based on items scored on the developed scales.

7. Developed scales' internal consistency and validity were evaluated. For validity, this was undertaken by correlating developed scales' scores with measures of mental pain, suicidal behaviors, and depression.

8. The distinct contributions of developed scales were evaluated. This was tested by regressing suicidal behavior scores simultaneously onto scores on the developed scales and examining the significance of obtained regression coefficients.

\section{RESULTS}

Table 1 reports fit statistics for the CFAs. Whereas no RMSEA, CFI, or TLI value indicated good or acceptable fit, SRMR values indicated good fit (one sample) or acceptable fit (five samples) for the three-factor model. Although fit measures tended to improve, in some instances from poor to acceptable fit, with ESEM (also Table 1), overall, interpretations of good fit or lack thereof were similar to those found for the CFAs.

\footnotetext{
${ }^{3}$ Although it was expected that factors of psychological pain would correlate, we deliberately chose an orthogonal rotation of the principal components solution so that subsequent item selection would yield scales that, although correlated, were not overly collinear.
} 
For each sample, the eigenvalue $>1$ heuristic indicated two components. Based on parallel analysis (1,000 replications), two components were indicated for five (all Portuguese and Canadian) of the six samples, and one component was favored in the American sample. Given the convergence of 11 of 12 indicators for two dimensions, two components were extracted in a dataset combining Samples 1 and 4 (one Portuguese sample and one Canadian sample), rotated to a varimax criterion, and the IEI applied. Based on IEIs, four items were selected for each of the two scales. Scale 1 (TDPPS items 2, 9, 11, 12) is labeled Pain Escape, and Scale 2 (TDPPS items 4, 15, 16, 17) is labeled Pain Emotions.

Table 1. Confirmatory Factor Analysis (CFA) and Exploratory Structural Equation Modeling (ESEM) Fit Statistics for a 3-Factor Model

\begin{tabular}{llllllllll}
\hline Sample & Model & $\chi^{2}$ & df & $\chi^{2} / \mathbf{d f}$ & RMSEA & CFI & TLI & SRMR & AIC \\
\hline Sample 1 & CFA & 633.55 & 116 & 5.46 & .116 & .878 & .857 & .065 & 12993.784 \\
Sample 2 & CFA & 495.30 & 116 & 4.27 & .119 & .860 & .836 & .074 & 9291.321 \\
Sample 3 & CFA & 650.45 & 116 & 5.61 & .109 & .870 & .847 & .063 & 15874.993 \\
Sample 4 & CFA & 592.38 & 116 & 5.11 & .134 & .847 & .820 & .064 & 9183.174 \\
Sample 5 & CFA & 443.00 & 116 & 3.82 & .107 & .885 & .865 & .064 & 10961.066 \\
Sample 6 & CFA & 514.68 & 116 & 4.44 & .129 & .892 & .873 & .047 & 9186.802 \\
& & & & & & & & & \\
Sample 1 & ESEM & 328.55 & 88 & 3.73 & .091 & .943 & .913 & .028 & 12744.789 \\
Sample 2 & ESEM & 240.46 & 88 & 2.73 & .086 & .944 & .913 & .030 & 9092.487 \\
Sample 3 & ESEM & 360.72 & 88 & 4.10 & .090 & .934 & .897 & .033 & 15641.260 \\
Sample 4 & ESEM & 260.06 & 88 & 2.96 & .093 & .945 & .915 & .029 & 8906.847 \\
Sample 5 & ESEM & 245.52 & 88 & 2.79 & .085 & .944 & .914 & .031 & 10819.595 \\
Sample 6 & ESEM & 264.77 & 88 & 3.01 & .099 & .952 & .926 & .026 & 8992.895 \\
\hline
\end{tabular}

For the eight items associated with the new scales, CFA and ESEM were applied to the two samples, separately, that were used in the principal components solution and application of the IEI to derive the new scales, and to the other four samples, separately, as cross-validation samples (Table 2).

Table 2. Eight-Item, 2-Factor Confirmatory Factor Analysis (CFA) and Exploratory Structural Equation Modeling (ESEM) Fit Statistics

\begin{tabular}{llllllllll}
\hline Sample & Model & $\chi^{2}$ & df & $\chi^{2} / \mathbf{d f}$ & RMSEA & CFI & TLI & SRMR & AIC \\
\hline Sample 1 & CFA & 141.08 & 19 & 7.43 & .139 & .921 & .883 & .077 & 6258.489 \\
Sample 2 & CFA & 55.13 & 19 & 2.90 & .091 & .965 & .948 & .063 & 4285.179 \\
Sample 3 & CFA & 142.38 & 19 & 7.49 & .130 & .926 & .890 & .062 & 7234.352 \\
Sample 4 & CFA & 103.29 & 19 & 5.44 & .139 & .928 & .893 & .059 & 4306.126 \\
Sample 5 & CFA & 113.34 & 19 & 5.97 & .142 & .918 & .879 & .079 & 5095.847 \\
Sample 6 & CFA & 61.77 & 19 & 3.25 & .105 & .967 & .951 & .040 & 4609.961 \\
& & & & & & & & & \\
Sample 1 & ESEM & 39.74 & 13 & 3.06 & .079 & .983 & .963 & .022 & 6169.149 \\
Sample 2 & ESEM & 16.72 & 13 & 1.29 & .035 & .996 & .992 & .016 & 4258.779 \\
Sample 3 & ESEM & 64.14 & 13 & 4.03 & .101 & .969 & .933 & .027 & 7168.122 \\
Sample 4 & ESEM & 44.13 & 13 & 3.39 & .102 & .973 & .942 & .024 & 4258.967 \\
Sample 5 & ESEM & 57.03 & 13 & 4.39 & .118 & .962 & .917 & .030 & 5051.542 \\
Sample 6 & ESEM & 27.02 & 13 & 2.08 & .073 & .989 & .976 & .022 & 4587.219 \\
\hline
\end{tabular}

For the six CFAs, only one RMSEA indicated at least acceptable fit $(\leq .10)$, all CFIs indicated acceptable fit $(\geq .90)$ with two exceeding the .95 criterion for good fit, two TLIs met or exceeded the .95 criterion for good fit, and all SRMRs met the .08 or less criterion for a good fit. For the six ESEMs, one RMSEA met the .06 or less criterion for good fit and four met the criterion for acceptable fit $(\leq .10)$, all CFIs met the criterion for a good fit, three TLIs met the criterion of .95 for a good fit with the other three meeting a .90 criterion for acceptable fit, and all SRMRs met the standard for a good fit. Of note, for each sample, the AIC 
value for the 8-item, 2 -factor solution was approximately half $(M=.48$; Range $=.46$ to .51$)$ the value associated with the corresponding 17-item, 3-factor solution. With results across criteria and samples generally providing acceptable support for a two-factor model for the eight items, ESEM was subsequently applied to all samples combined yielding fit statistics: $\chi^{2}=143.15, \chi^{2} / \mathrm{df}=11.01$, RMSEA $=.078$ [90\% CI $.067, .090], \mathrm{CFI}=.985, \mathrm{TLI}=.967 ; \mathrm{SRMR}=.017, \mathrm{AIC}=32412.903$. The standardized solution and associated TDPPS items are reported in Table 3 , and the two factors correlated $.53, p<.01$.

For the derived scales of Pain Escape and Pain Emotions, Table 4 reports scale score properties. For internal consistency reliability, all Cronbach $\alpha$ 's exceeded .83, all McDonald $\omega$ 's surpassed .85, and all scale mean interitem correlations were greater than .50. For scale validity, correlations with another psychological pain measure, the Psychache Scale, varied between .36 and .89 (Median = .67). As statistical predictors of suicidal behavior, correlations with the SBQ-R ranged from .41 to .77 (Median = .58). Correlations with a related but distinct construct, depression, measured by the CES-D, varied between .38 and .78 (Median $=.58)$. 
Table 3. Factor Loadings, Residuals, and Communalities for 8-Item, 2-Factor Exploratory Structural Equation Modeling on All Samples Combined (N = 1,627)

\begin{tabular}{|c|c|c|c|c|c|c|c|c|c|c|c|}
\hline \multirow[b]{3}{*}{$\begin{array}{l}\text { TDPPS Item } \\
\text { No. }\end{array}$} & \multirow[b]{3}{*}{ Abridged Content } & \multicolumn{6}{|c|}{ Standardized Loadings } & \multicolumn{3}{|c|}{ Standardized Residuals } & \multirow[t]{3}{*}{$\mathbf{h}^{2}$} \\
\hline & & \multicolumn{3}{|c|}{ Pain Escape Factor } & \multicolumn{3}{|c|}{ Pain Emotions Factor } & \multirow[b]{2}{*}{$\begin{array}{l}\text { Estimate } \\
\text { (Est.) }\end{array}$} & \multirow[b]{2}{*}{$S E$} & \multirow[b]{2}{*}{ Est./SE } & \\
\hline & & $\begin{array}{l}\text { Estimate } \\
\text { (Est.) }\end{array}$ & $S E$ & Est./SE & $\begin{array}{l}\text { Estimate } \\
\text { (Est.) }\end{array}$ & $S E$ & Est./SE & & & & \\
\hline 2 & Death is only escape from pain & .90 & .01 & 90.29 & -.00 & .01 & -.23 & .19 & .01 & 14.31 & .91 \\
\hline 9 & Suicide is relief from pain & .91 & .01 & 79.95 & -.01 & .01 & -.46 & .18 & .01 & 13.48 & .82 \\
\hline 11 & Can't escape from hole of pain & .60 & .02 & 30.83 & .31 & .02 & 14.59 & .35 & .02 & 22.60 & .65 \\
\hline 12 & Almost killed self to stop pain & .68 & .02 & 35.40 & .11 & .02 & 4.84 & .44 & .02 & 24.48 & .56 \\
\hline 4 & Sad memories of failure are painful & .16 & .03 & 5.85 & .62 & .02 & 28.13 & .49 & .02 & 24.91 & .52 \\
\hline 15 & Pain is emotional not physical & -.07 & .03 & -2.47 & .88 & .02 & 44.43 & .29 & .02 & 16.69 & .81 \\
\hline 16 & Frequent bad memories cause pain & -.00 & $<.01$ & -1.93 & .80 & .01 & 67.20 & .37 & .02 & 19.82 & .73 \\
\hline 17 & Mental pain exceeds physical pain & .09 & .03 & 3.25 & .81 & .02 & 43.00 & .26 & .02 & 17.07 & .74 \\
\hline
\end{tabular}

Table 4. Revised Scales' Psychometric Properties

\begin{tabular}{|c|c|c|c|c|c|c|c|}
\hline \multirow[t]{2}{*}{ Sample } & \multirow[t]{2}{*}{ Scale } & \multicolumn{3}{|c|}{ Internal Consistency Reliability } & \multicolumn{3}{|c|}{ Correlations } \\
\hline & & Cronbach's $\alpha$ & McDonald's $\omega$ & $\begin{array}{l}\text { Mean Interitem } \\
\text { Correlation }\end{array}$ & Psychache & SBQ-R & Depression \\
\hline Sample 1 & Pain Escape & .86 & .86 & .60 & .53 & .58 & .38 \\
\hline Sample 1 & Pain Emotions & .88 & .88 & .64 & .64 & .54 & .52 \\
\hline Sample 2 & Pain Escape & .86 & .86 & .60 & .36 & .41 & .35 \\
\hline Sample 2 & Pain Emotions & .89 & .89 & .65 & .59 & .42 & .52 \\
\hline Sample 3 & Pain Escape & .86 & .87 & .61 & .65 & .74 & .51 \\
\hline Sample 3 & Pain Emotions & .86 & .86 & 60 & .76 & .58 & .57 \\
\hline Sample 4 & Pain Escape & .84 & .86 & .55 & .68 & .66 & .59 \\
\hline Sample 4 & Pain Emotions & .90 & .90 & .69 & .66 & .58 & .64 \\
\hline Sample 5 & Pain Escape & .85 & .88 & .57 & .76 & .77 & .60 \\
\hline Sample 5 & Pain Emotions & .85 & .85 & .59 & .71 & .50 & .61 \\
\hline Sample 6 & Pain Escape & .93 & .94 & .74 & .89 & .64 & .78 \\
\hline Sample 6 & Pain Emotions & .86 & .86 & .51 & .79 & .59 & .78 \\
\hline
\end{tabular}


Table 5 reports simultaneous regressions of SBQ-R scores onto scores of the new scales of Pain Avoidance and Pain Emotions. Across samples, $R^{2}$ values ranged from .24 to .61 and, within each sample, scores on each of the two predictors explained significant, unique variance in suicidal behavior.

Table 5. Standardized Regression Coefficients for Predicting SBQ-R Total Scores from Revised TDPPS Scales

\begin{tabular}{lllllll}
\hline \multicolumn{7}{c}{ Sample } \\
\hline$R^{2}$ & Sample 1 & Sample 2 & Sample 3 & Sample 4 & Sample 5 & Sample 6 \\
\cline { 2 - 7 } Pain Escape & $.40^{* * *}$ & $.24^{* * *}$ & $.59^{* * *}$ & $.48^{* * *}$ & $.61^{* * *}$ & $.45^{* * *}$ \\
Pain Emotions & $.41^{* * *}$ & $.28^{* * *}$ & $.59^{* * *}$ & $.49^{* * *}$ & $.70^{* * *}$ & $.44^{* * *}$ \\
\hline
\end{tabular}

\section{DISCUSSION}

The purpose of the present study was to investigate the factor structure of the TDPPS in Western samples. Testing the structure of the measure evaluates the potential merits of its use with Western populations. Also, it tests the three-dimensional model of psychological pain, thus contributing to the clarification of this construct's dimensionality. We hypothesized that a 3-factor solution would replicate across samples. The three dimensions' scores would demonstrate high internal consistency and relate to another psychological pain measure and a related but distinct construct, depression. We also hypothesized that the three dimensions, in particular pain avoidance, would explain significant, unique variance in suicidal behaviors.

Current analyses found that, in non-Chinese samples, the nature of the TDPPS did not conform to its hypothesized structure and proposed scoring key of affective, cognitive, and behavioral scales. Instead, a two-dimensional structure of pain escape and pain emotions emerged. Based on this solution, a new 8item, two-scale scoring key is proposed. This revision has a structure that replicates across samples and provides scale scores that have promising psychometric properties. This 8-item revision could be a more efficient, stand-alone version in that it has less than half the items of the original TDPPS or, if preferred, it could represent an alternative scoring for the full 17-item TDPPS. Scale scores, based on the twodimensional solution, are related to scores of another mental pain measure and scores for a distinct but related construct, depression. As hypothesized, the avoidance (escape) dimension significantly explained a greater proportion of variance in suicidal behaviors.

A question arises as to why the three-factor TDPPS structure is found in the original Chinese sample but not in the current, Western samples. A possible explanation may be the double-barreled nature of some items. For example, item 3, "The pain I'm feeling is nearly unexplainable and comes out of nowhere," seems to address two issues, not one, and, as a result, could blur the underlying structure. Nevertheless, despite potential structural issues, non-Chinese versions of the TDPPS demonstrate substantial merit (e.g., Campos, Holden, et al., 2019; Campos, Simões, et al., 2019), indicating that the measure has strengths that are to be noted, and suggesting that a revised scoring system may be appropriate. Results also raise the question regarding whether psychological pain would be better conceptualized as a three-facet or a two-facet construct. Specifically, the affective and cognitive dimensions may be highly collinear and, practically, unamenable to assessing different facets of the same construct.

Potential limitations to our research exist. First, results are for measures translated among Chinese, Portuguese, and English languages. Although multiple bilingual psychologists and a back-translation by a bilingual translator were involved, translations can be fallible. Second, measures were self-report and relied on participants being able to and willing to provide honest answering. Third, our design was crosssectional and limited the ability to draw causal inferences among the constructs studied. Fourth, participants were from nonclinical samples. Fifth, although similar samples were used, they may not be entirely comparable. Replication with other samples, other data collection modes (e.g., reports of significant others), longitudinal designs, and clinical patients will serve to establish the generalizability of current findings.

In conclusion, the observed Western data do not support the hypothesized three-factor structure of the TDPPS. Results suggest the TDPPS assesses two dimensions, pain escape, and pain emotions. Scales for these two dimensions can be scored from the TDPPS, and they demonstrate appropriate psychometric properties.

Assessing suicide risk is a complex but indispensable clinical task. Psychometrically sound measures such as the TDDPS are important tools whose psychometric properties (e.g., structure, reliability, validity) should be made available for relevant health professionals. In assessing the psychological experience of pain, the tendency to avoid pain may be crucial both in the initial clinical assessment of at-risk individuals 
and in their follow-up assessment. Evaluating psychological pain may even be relevant in assessing persons at risk for suicide even when they do not report significant suicide ideation. Further, assessing psychological pain may be more acceptable to clients than is inquiring directly about serious suicidal ideation or suicidal behavior and, as such, may address issues of concealment of suicidal urges that some individuals, such as perfectionists, may have (Flett et al., 2014).

\section{REFERENCES}

Berlim, M.T., Mattevi, B.S., Pavanello, D.P., Caldieraro, M.A., Fleck, M.P.A., Wingate, L.R., \& Joiner, T.E. (2003). Psychache and suicidality in adult mood disordered outpatients in Brazil. Suicide and LifeThreatening Behavior, 33, 242-248. https://doi.org/10.1521/suli.33.3.242.23220

Campos, R. C., \& Holden R. R. (2019). Portuguese version of the Suicidal Behaviors Questionnaire-Revised. Validation data and the establishment of a cut-score for screening purposes. European Journal of Psychological Assessment, 35, 190-195. https://doi.org/10.1027/1015-5759/a000385

Campos, R. C., Holden, R. R., \& Gomes, M. (2018). Assessing psychache as a suicide risk variable: Data with the Portuguese version of the Psychache Scale. Death Studies, 43, 527-533. https://doi.org/10.1080/07481187.2018.1493002

Campos, R.C., Holden, R.R., \& Lambert, C.E. (2019). Avoidance of psychological pain and suicidal ideation in community samples: Replication across two countries and two languages. Journal of Clinical Psychology, 75, 2160-2168. https://doi.org/10.1002/jclp.22837

Campos, R.C., Holden, R.R., Spínola, J., Marques, D., \& Lambert, C.E. (2019). The dimensionality of suicide behaviors: Results within two samples from two different countries. Omega: Journal of Death and Dying. Advanced online: https://doi.org/10.1177/0030222819882849

Campos, R.C., Simões, A., Costa, S., Pio, A.S., \& Holden, R.R. (2019). Psychological pain and suicidal ideation in undergraduates: The role of pain avoidance. Death Studies, 44, 375-378. https://doi.org/10.1080/07481187.2018.1554610

Demirkol, M., Tamam, L., Namli, Z., Karaytuğ, M., \& Uğur, K. (2019). Association of psychache and alexithymia with suicide in patients with schizophrenia. The Journal of Nervous and Mental Disease, 207, 668-674. https://doi.org/10.1097/NMD.0000000000001023

Ducasse, D., Holden, R.R., Boyer, L., Artero, S., Calati, R., Guillaume, S., Courtet, P., \& Olie, E. (2018). Psychological pain in suicidality: A meta-analysis. The Journal of Clinical Psychiatry, 79(3):16r10732. https://doi.org/10.4088/JCP.16r10732

Erford, B.T., Johnson, E., \& Bardoshi, G. (2016). Meta-analysis of the English version of the Beck Depression Inventory-Second Edition. Measurement and Evaluation in Counseling and Development, 49, 3-33. https://doi.org/10.1177/0748175615596783

Flett, G. L., Hewitt, P. L., \& Heisel, M. J. (2014). The destructiveness of perfectionism revisited: Implications for the assessment of suicide risk and the prevention of suicide. Review of General Psychology, 18, 156-172. https://doi.org/1doi:10.1037/gpr0000011

Flynn, J.J., \& Holden, R.R. (2007). Predictors of suicidality in a sample of suicide attempters. Canadian Psychology, 48, 2a, 317.

Gonçalves, B., \& Fagulha, T. (2004). The Portuguese version of the Center for Epidemiologic Studies Depression Scale (CES-D). European Journal of Psychological Assessment, 20, 339-348. https://doi.org/10.1027/1015-5759.20.4.339

Holden, R.R. (1996). The Holden Psychological Screening Inventory manual. Multi-Health Systems.

Holden, R.R., Kerr, P.S., Mendonca, J.D., \& Velamoor, V.R. (1998). Are some motives more linked to suicide proneness than others? Journal of Clinical Psychology, 54, 569-576. https://doi.org/10.1002/(SICI)1097-4679(199808)54:5<569::AID-JCLP2>3.0.CO;2-G

Holden, R.R., Mehta, K., Cunningham, E.J., \& McLeod, L.D. (2001). Development and preliminary validation of a scale of psychache. Canadian Journal of Behavioural Science, 33, 224-232. https://doi.org/10.1037/h0087144

Jackson, D.N., Helmes, E., Hoffmann, H., Holden, R.R., Jaffe, P., Reddon, J.R., \& Smiley, W. C. (1989). The Basic Personality Inventory manual. Sigma Assessment Systems.

Leenaars, A.A., \& Lester, D. (2005). A note on Shneidman's psychological pain assessment scale. Omega: Journal of Death and Dying, 50, 301-307. https://doi.org/10.2190/WH9X-80M3-NJ54-5GCU

Li, H., Fu, R., Zou, Y., \& Cui, Y. (2017). Predictive roles of three-dimensional psychological pain, psychache, and depression in suicidal ideation among Chinese college students. Frontiers in Psychology, 8, 1-8. https://doi.org/10.3389/fpsyg.2017.01550

Li, H., Xie, W., Lou, X., Fu, R., Shi, C., Ying, X., ... Wang, X. (2014). Clarifying the role of psychological pain in the risks of suicidal ideation and suicidal acts among patients with major depressive episodes. Suicide and Life-Threatening Behavior, 44, 78-88. https://doi.org/10.1111/sltb.12056 
Marsh, H., Morin, A., Parker, P., \& Kaur, G. (2014). Exploratory structural equation modeling: An integration of the best features of exploratory and confirmatory factor analysis. Annual Review of Clinical Psychology, 10, 85-110. https://doi.org/10.1146/annurev-clinpsy-032813-153700

Mee, S., Bunney, B.G., Bunney, W.E., Hetrick, W., Potkin, S.G., \& Reist, C. (2011). Assessment of psychological pain in major depressive episodes. Journal of Psychiatric Research, 45, 1504-1510. https://doi.org/10.1016/j.jpsychires.2011.06.011

Mills, J. F., Green, K., \& Reddon, J. R. (2005). An evaluation of the Psychache Scale on an offender population. Suicide and Life-Threatening Behavior, 35, 570-580. https://doi.org/10.1521/suli.2005.35.5.570

National Institute of Statistics (2019). Causas de morte 2017. Instituto Nacional de Estatística.

Osman, A., Bagge, C.L., Gutierrez, P.M., Konick, L.C., Kopper, B.A., \& Barrios, F.X. (2001). The Suicidal Behaviors Questionnaire-Revised (SBQ-R): Validation with clinical and nonclinical samples. Assessment, 8, 443-454. https://doi.org/10.1177/107319110100800409

Pereira, E.J., Kroner, D.G., Holden, R.R., \& Flamenbaum, R. (2010). Testing Shneidman's model of suicidality in incarcerated offenders and in undergraduates. Personality and Individual Differences, 49, 912-917. https://doi.org/10.1016/j.paid.2010.07.029

Radloff, L.S. (1977). The CES-D scale: A self-report depression scale for research in the general population. Applied Psychological Measurement, 1, 385-401. https://doi.org/10.1177/014662167700100306

Roxborough, H.M., Hewitt, P.L., Kaldas, J., Flett, G.L., Caelian, C.M., Sherry, S., \& Sherry, D. L. (2012). Perfectionistic self-presentation, socially prescribed perfectionism, and suicide in youth: A test of the perfectionism social disconnection model. Suicide and Life-Threatening Behavior, 42, 217-233. https://doi.org/10.1111/j.1943-278X.2012.00084.x

Sellbom, M., \& Tellegen, A. (2019). Factor analysis in psychological assessment research: Common pitfalls and recommendations. Psychological Assessment, 31, 1428-1441. http://dx.doi.org/10.1037/pas0000623

Shneidman, E.S. (1993). Suicide as psychache. Journal of Nervous and Mental Disease, 181, 145-147. https://doi.org/10.1097/00005053-199303000-00001

Shneidman, E.S. (1994). Clues to suicide, reconsidered. Suicide and Life-Threatening Behavior, 24, 395-397.

Sun, X., Li, H., Song, W., Jiang, S., Shen, C., Wang, X. (2020). ROC analysis of three-dimensional psychological pain in suicide ideation and suicide attempt among patients with major depressive disorder. Journal of Clinical Psychology, 76, 210-227. https://doi.org/10.1002/jclp.22870

Troister, T., D’Agata, M.T., \& Holden. R.R. (2015). Suicide risk screening: Comparing the Beck Depression Inventory-II, Beck Hopelessness Scale, and Psychache Scale in undergraduates. Psychological Assessment, 27, 1500-1506. https://doi.org/10.1037/pas0000126

Troister, T., \& Holden, R.R. (2010). Comparing psychache, depression, and hopelessness in their associations with suicidality: A test of Shneidman's theory of suicide. Personality and Individual Differences, 49, 689-693. https://doi.org/10.1016/j.paid.2010.06.006

Troister, T., \& Holden, R.R. (2013). Factorial differentiation among depression, hopelessness, and psychache in statistically predicting suicidality. Measurement \& Evaluation in Counseling \& Development, 46, 50-63. https://doi.org/10.1177/0748175612451744

Verrocchio, M. C., Carrozzino, D., Marchetti, D., Andreasson, K., Fulcheri, M., \& Bech, P. (2016). Mental pain and suicide: A systematic review of the literature. Frontiers in Psychiatry, 7, 108. https://doi.org/10.3389/fpsyt.2016.00108

Waring, E.M., Holden, R.R., \& Wesley, S. (1998). Development of the Marital Self-Disclosure Questionnaire (MSDQ). Journal of Clinical Psychology, 54, 817-824. https://doi.org/10.1002/(SICI)10974679(199810)54:6<817::AID-JCLP9>3.0.CO;2-D

World Health Organization (2021). Suicide. https://www.who.int/news-room/fact-sheets/detail/suicide

Xie, W., Li, H., Luo, X., Fu, R., Ying, X., Wang, N., ... Shi, C. (2014). Anhedonia and pain avoidance in the suicidal mind: Behavioral evidence for motivational manifestations of suicidal ideation in patients with major depressive disorder. Journal of Clinical Psychology, 70, 681-692. https://doi.org/10.1002/jclp.22055

Zwick, W.R. \& Velicer W.F. (1986). Comparison of five rules for determining the number of components to retain. Psychological Bulletin, 99, 432-442. https://doi.org/10.1037/0033-2909.99.3.432

$\begin{array}{ll}\text { Historial do artigo } & \\ \text { Recebido } & 07 / 2020 \\ \text { Aceite } & 02 / 2021 \\ \text { Publicado online } & 03 / 2021 \\ \text { Publicado } & 06 / 2021\end{array}$

